\title{
Critical appraisal of paroxetine for the treatment of vasomotor symptoms
}

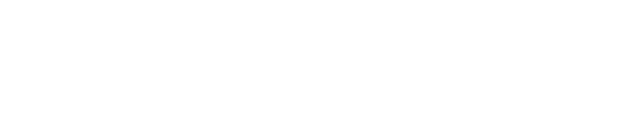

\section{Dana G Carroll ${ }^{1,2}$ \\ Katelin M Lisenby ${ }^{1,2}$ \\ Tracy L Carter ${ }^{3}$}

'Department of Pharmacy Practice, Harrison School of Pharmacy, Auburn University, Auburn, AL, USA; ${ }^{2}$ Department of Family Medicine, College of Community Health Sciences, University of Alabama, University Medical Center, Tuscaloosa, AL, USA; ${ }^{3}$ Department of Pharmacy, DCH Regional Medical Center, Tuscaloosa, AL, USA
Correspondence: Dana G Carroll Department of Pharmacy Practice, Harrison School of Pharmacy, I327D Walker Building, Auburn University, AL 36849, USA

$\mathrm{Tel}+|205348289|$

Fax +l 2053482889

Email dgc000I@auburn.edu
Background: Vasomotor symptoms (VMS), characterized by hot flashes and night sweats, are the most commonly reported symptoms associated with estrogen deficiency during menopause and occur in up to $70 \%$ of women. The goal of treatment is to reduce the frequency and severity of symptoms. Although hormone therapy (HT) is generally recommended as first-line treatment, it is not appropriate for all patients. Antidepressants, specifically selective serotonin reuptake inhibitors, have been evaluated and utilized internationally for alternative treatment for VMS. In 2013, paroxetine mesylate (Brisdelle ${ }^{\circledR}$ ) received a US Food and Drug Administration-labeled indication for moderate-to-severe hot flashes, making it the first nonhormonal treatment for VMS associated with menopause. The objective of this review is to critically evaluate available clinical data regarding the efficacy and safety of paroxetine for the treatment of VMS in menopausal women.

Methods: MEDLINE, PubMed, and Google Scholar were searched using the keywords paroxetine, vasomotor symptoms, hot flashes, and menopause. Searches were limited to humans, English language, and clinical trial design with a primary outcome of hot flash/vasomotor changes.

Results: Paroxetine (hydrochloride and mesylate) has been associated with a 33\%-67\% reduction in hot flash frequency with 6-12 weeks of treatment compared to $13.7 \%-37.8 \%$ reductions with placebo in patients both with and without a history of breast cancer. It was also associated with significant reductions in hot flash severity. Benefits of treatment persisted through 24 weeks in the study of the longest duration. Most adverse effects reported were of mild-to-moderate severity, with improved tolerability associated with lower doses $(7.5-12.5 \mathrm{mg} /$ day $)$.

Conclusion: Paroxetine is a safe and effective therapy for the treatment of VMS during menopause. Paroxetine (7.5-12.5 mg/day) should be considered a first-line therapy option for VMS in patients when HT is either inappropriate or intolerable.

Keywords: paroxetine, vasomotor symptoms, hot flashes, menopause

\section{Background}

The onset of menopause can be an extremely challenging life change for many women. The timing of when natural menopause occurs is affected by race, ethnicity, and lifestyle. ${ }^{1}$ The average age of onset in industrialized nations is in the early $50 \mathrm{~s}$ but occurs several years earlier in developing countries. ${ }^{1,2}$ Therefore, most women spend one-third of their lifespan in a postmenopausal state. Menopause is defined as the permanent loss of menses for 1 year following ovarian failure, which results in an estrogen- and progesterone-deficient state. ${ }^{2,3}$ This decline in estrogen and progesterone levels is known to contribute to several signs and symptoms associated with menopause, such as hot flashes, vaginal atrophy, dyspareunia, memory problems, mood changes, and insomnia. ${ }^{2-4}$ These physical and psychological changes can affect the quality of life of up to $85 \%$ menopausal women. ${ }^{2-4}$ 
The most common and troublesome symptoms are the hot flashes and night sweats, known as vasomotor symptoms (VMS). ${ }^{2-4}$ VMS occur in $>70 \%$ of menopausal women, and one-third of women first experience hot flashes during perimenopause, the years leading up to menopause. ${ }^{2,3}$ Hot flashes frequently manifest as flushing, warmth around the face and neck, perspiration, and chills. Hot flashes are further characterized by a sudden onset, either without warning or after a trigger such as caffeine or stress, and generally last 1-5 minutes. These events can occur multiple times daily and usually persist for $1-4$ years, although they may continue for $>10$ years in some women. ${ }^{2-4}$ Although the pathophysiology of hot flashes has not been fully elucidated, it has been suggested that a decline in estrogen and progesterone levels triggers alterations to the neuroendocrine system, including changes in serotonin and norepinephrine levels, and leads to thermoregulatory dysfunction in the hypothalamus. ${ }^{2,3}$ Changes in serotonin and norepinephrine are associated with increases in core body temperatures and narrowing of the thermoregulatory zone. ${ }^{4}$

Treatment of VMS is directed at reducing both the severity and the frequency of hot flashes. ${ }^{5}$ Hormone therapy (HT) is considered to be the most effective treatment for VMS and is therefore recognized as a first-line option., ${ }^{2,3}$ It is recommended for the management of VMS by the American Association of Clinical Endocrinologists (AACE) and the American College of Obstetricians and Gynecologists (ACOG) ${ }^{2,3} \mathrm{HT}$ is also supported in a global consensus statement endorsed by the North American Menopause Society (NAMS), the European Menopause and Andropause Society, the International Menopause Society (IMS), the Asia Pacific Menopause Federation, the American Society of Reproductive Medicine, the Endocrine Society, and the International Osteoporosis Foundation. ${ }^{6}$

Although HT is noted to be efficacious, its use is not without concerns. ${ }^{2,3,6}$ The safety concerns of HT were well established after the Women's Health Initiative trials were published in 2002.,7-9 Women considering HT must evaluate the increased risks of thromboembolism and breast cancer. The absolute risk increase is low but varies based on the use of estrogen monotherapy or therapy in combination with progestin, baseline risks, age, years since menopause, and possibly route of administration. ${ }^{2} \mathrm{HT}$ is contraindicated in women with a history of thromboembolism and breast cancer. ${ }^{3,5-7}$ Both of these serious adverse events are rare in patients $<60$ years of age or those within 10 years of menopause; therefore, HT is a suitable option for most women. ${ }^{7}$ However, alternative treatments are needed for women in whom HT is either inappropriate or intolerable, those having a higher baseline risk for adverse events, or those preferring to not use HT.

Antidepressants, particularly selective serotonin reuptake inhibitors (SSRIs), are recognized as an acceptable alternative treatment for the management of VMS associated with menopause. ${ }^{3,7}$ ACOG, AACE, IMS, and NAMS all suggest that SSRIs constitute an effective alternative to HT for the treatment of VMS with a growing body of evidence but note the need for more studies, particularly in direct comparison with HT. ${ }^{2,3,5,7}$ SSRIs contribute to VMS management through two proposed mechanisms. These include decreasing blood flow to the skin to counter the vasodilation during flushing and lowering core body temperature through central vasodilation to negate the effects that occur during menopause due to the narrowed thermoregulatory zone. ${ }^{4}$

There has been an increasing amount of evidence to support the use of several SSRIs for VMS management, with paroxetine being one of the most extensively studied. ${ }^{10-15}$ In 2013, the US Food and Drug Administration (FDA) approved paroxetine mesylate (Brisdelle ${ }^{\circledR}$; Noven Therapeutics, LLC, Miami, FL, USA) for the treatment of moderate-to-severe VMS. The approval was based largely on the results of two recently published randomized controlled trials (RCTs) and made paroxetine mesylate the first nonhormonal treatment indicated for VMS associated with menopause. ${ }^{10,16}$ The evidence for the use of paroxetine (as the hydrochloride $[\mathrm{HCl}]$ and mesylate salts) in the management of VMS is examined in this review.

\section{Search criteria}

This is a systematic review to evaluate the use of paroxetine to treat VMS associated with menopause (natural, chemotherapy induced, or surgically induced). We searched the following databases using these search terms in various combinations.

- Medline: "paroxetine" [MESH], "vasomotor" [MESH], "hot flashes" [MESH], and "menopause" [MESH]

- PubMed: "paroxetine", "vasomotor", "hot flashes", and "menopause"

- Google Scholar: "paroxetine", "vasomotor", "hot flashes", and "menopause".

Inclusion criteria included English language trials, prospective and retrospective cohorts or case-control trials, prospective RCTs, paroxetine vs placebo or active treatment, and a primary outcome of hot flash/vasomotor changes. We identified ten trials, ${ }^{10-15,17-20}$ four of which were excluded. ${ }^{17-20}$ The reasons for exclusion included the assessment of nonclinical outcomes (one assessing pharmacokinetic properties, ${ }^{17}$ one 
assessing brain-derived neurotrophic factor, ${ }^{18}$ and one assessing cytokine levels ${ }^{19}$ ), whereas one did not assess hot flashes or VMS as the primary outcome. ${ }^{20}$

\section{Assessments of VMS in clinical trials}

Studies assessing VMS typically require enrolled patients to $\log$ the frequency of hot flash occurrences into a diary on a daily basis to collect data. In addition, some studies require patients to both rank the severity and record the duration of each hot flash in the diary. Investigators can then use this information to assess the frequency and severity of hot flashes. While this can be clinically useful information to report a change in frequency, more validated and useful instruments are available to assess changes in hot flashes in menopausal women. The Hot Flash Composite Score has patients rank the severity of their hot flashes (which is given a numerical score) multiplied by the frequency and a daily score is calculated. ${ }^{11}$ (Refer Table 1 for more specific details on each instrument.) Higher scores with this assessment tool correlate with more severe VMS. ${ }^{11}$ The Greene Climacteric Score (GCS) is a validated instrument utilized to assess VMS and assesses four domains (psychological, somatic, VMS, and sexual dysfunction). ${ }^{11}$ Overall scores can range from 0 to 63 , with higher scores indicating more severe symptoms. The VMS domain subscore in the GCS ranges from 0 to 6 , with higher scores indicating more severe symptoms. ${ }^{13}$ Another instrument, the Weekly Hot Flash Severity Index, assesses and calculates a score on a weekly basis. ${ }^{10}$ Higher scores are associated with more severe VMS. ${ }^{10}$

While most studies assess actual changes in the frequency and/or severity of hot flashes as the primary outcome, there are other aspects that may be assessed as valid secondary outcomes. One of the most popular aspects assessed as a secondary outcome is the patient perception and satisfaction with changes in hot flash occurrence and/or severity after initiating therapy. One validated instrument utilized to assess women's perceptions of improvement in their hot flashes is the Patient Global Impression of Improvement (PGI-I). ${ }^{10,16}$ The instruments previously discussed are utilized in the studies included in this review.

\section{Study populations primarily with breast cancer}

Paroxetine $\mathrm{HCl}$ initially was studied in a small, open-label pilot study $(n=30)$ by Stearns et $\mathrm{al}^{13}$ in women with a history of breast cancer. Seventy-four percent age of patients enrolled were experiencing $\geq 5$ hot flashes per day. All patients took

Table I Instruments used in trials to assess vasomotor symptoms (VMS)

\begin{tabular}{|c|c|c|}
\hline Instrument & Score & Clinical interpretation \\
\hline Hot Flash Composite Score"I & $\begin{array}{l}\text { Each level of hot flash severity (mild }=I \text {, } \\
\text { moderate }=2 \text {, severe }=3 \text {, very severe }=4 \text { ) } \times \\
\text { daily number of hot flashes in that category } \\
\text { A daily score is compiled from the sum of } \\
\text { the four resulting values }\end{array}$ & $\begin{array}{l}\text { Higher scores correlate with more severe } \\
\text { symptoms }\end{array}$ \\
\hline Greene Climacteric Scale ${ }^{12}$ (validated) & $\begin{array}{l}\text { Consists of } 2 \text { I items scored as not at all }=0 \text {, } \\
\text { a little }=I \text {, quite a bit }=2 \text {, extremely }=3 \\
\text { to assess four domains: psychological } \\
\text { (items I-II; score range } 0-33) \text {, somatic } \\
(I 2-I 8 ; 0-2 I) \text { VMS }(I 9-20 ; 0-6) \text {, and sexual } \\
\text { dysfunction }(2 I ; 0-3)\end{array}$ & $\begin{array}{l}\text { Score range: 0-63 (higher scores } \\
\text { correlate with more severe symptoms); } \\
\text { VMS subscore: } 0-6 \text { (scores of } 0-2 \text { indicate } \\
\text { no to mild hot flashes, and scores of 3-6 } \\
\text { indicate moderate-to-severe hot flashes) }\end{array}$ \\
\hline Weekly hot flash severity score ${ }^{10}$ & $\begin{array}{l}\text { Mild = sensation of heat without sweating } \\
\text { Moderate = sensation of heat with sweating, } \\
\text { able to continue activity } \\
\text { Severe = sensation of heat with sweating, } \\
\text { causes cessation of activity } \\
(2 \times \text { number of moderate })+(3 \times \text { number } \\
\text { of severe) divided by the total number of } \\
\text { moderate and severe }\end{array}$ & $\begin{array}{l}\text { Higher scores correlate with more severe } \\
\text { symptoms }\end{array}$ \\
\hline $\begin{array}{l}\text { Patient Global Impression of Improvement }{ }^{11,16} \\
\text { (validated) }\end{array}$ & $\begin{array}{l}\text { "Compared to before starting the study } \\
\text { medication, how would you describe your } \\
\text { hot flushes now?" }\end{array}$ & $\begin{array}{l}\text { Satisfied = (I) Very much better or } \\
\text { (2) Much better }\end{array}$ \\
\hline & $\begin{array}{l}\text { (I) Very much better, (2) Much better, (3) } \\
\text { A little better, (4) No change, (5) A little } \\
\text { worse, (6) Much worse, (7) Very much } \\
\text { worse }\end{array}$ & Unsatisfied = otherwise \\
\hline
\end{tabular}


$10 \mathrm{mg}$ of paroxetine $\mathrm{HCl}$ daily for 1 week and then $20 \mathrm{mg}$ daily for 5 weeks. The primary outcomes assessed were change in hot flash frequency and hot flash score (frequency $x$ intensity). Hot flash frequency was decreased by $67 \%$ (confidence interval [CI]: 56\%-79\%) at the end of 6 weeks and hot flash scores decreased by $75 \%$ (CI: 66\%-85\%). At the end of the study, $83 \%(n=25)$ chose to continue paroxetine $\mathrm{HCl}$ even after the study was completed. Nine percent age $(n=3)$ dropped out before the trial was complete due to somnolence $(n=2)$ and anxiety $(n=1)$. The most common adverse effects reported were somnolence, dry mouth, nausea, and dizziness (Table 2). Limitations of this study include the following: open-label study design, very small study population, study population exclusive for breast cancer survivors, and short duration.

Another small open-label pilot study ( $\mathrm{n}=13)$ followed this initial study, and it too was conducted exclusively in a breast cancer survivor population. ${ }^{14}$ These patients had to experience hot flashes of at least moderate intensity ( $\geq 3$ on a scale of 1-5) to be enrolled. Patients were assigned to take paroxetine $\mathrm{HCl} 10 \mathrm{mg}$ daily for 3 days, followed by $20 \mathrm{mg}$ daily thereafter for 6 weeks. The primary outcome assessed was change in the hot flash severity. Hot flash severity was $3.62 \pm 0.51$ at baseline and $2.08 \pm 1.32$ at the end of the study $(P=0.002)$. Adverse effects were not reported. Limitations of this study include the following: open-label study design, very small study population, study population consisting exclusively breast cancer survivors, and short duration.

In 2005, Stearns et al ${ }^{15}$ conducted a double-blind, randomized, controlled, crossover study in 151 menopausal women, with the majority being breast cancer survivors. This study consisted of a 4-week active treatment period, a 4-week placebo period, and a 1-week washout period between the crossovers. There were four groups within the study: $10 \mathrm{mg}$ paroxetine $\mathrm{HCl}$ followed by placebo, placebo followed by $10 \mathrm{mg}$ paroxetine $\mathrm{HCl}, 20 \mathrm{mg}$ paroxetine $\mathrm{HCl}$ followed by placebo, and placebo followed by $20 \mathrm{mg}$ paroxetine $\mathrm{HCl}$. The primary outcomes were change in hot flash frequency and hot flash composite scores. The baseline mean daily hot flash frequency ranged from 6.9 to 7.8 among the four groups and was of moderate intensity. Hot flash frequency was decreased by $40.6 \%$ (standard error [SE]: 5.1 ) vs $13.7 \%$ (SE: 5.6 ), $P=0.0006$, with $10 \mathrm{mg}$ paroxetine $\mathrm{HCl}$ vs placebo. Hot flash frequency was significantly decreased by $51.7 \%$ (SE: 5.3 ) vs 26.6\% (SE: 7.0), $P=0.0002$, with $20 \mathrm{mg}$ paroxetine $\mathrm{HCl}$ vs placebo. Composite scores also significantly decreased with $10 \mathrm{mg}$ and $20 \mathrm{mg}$ of paroxetine $\mathrm{HCl}$ vs placebo arms (Table 2 shows the complete results). Forty-four (29\%) patients were

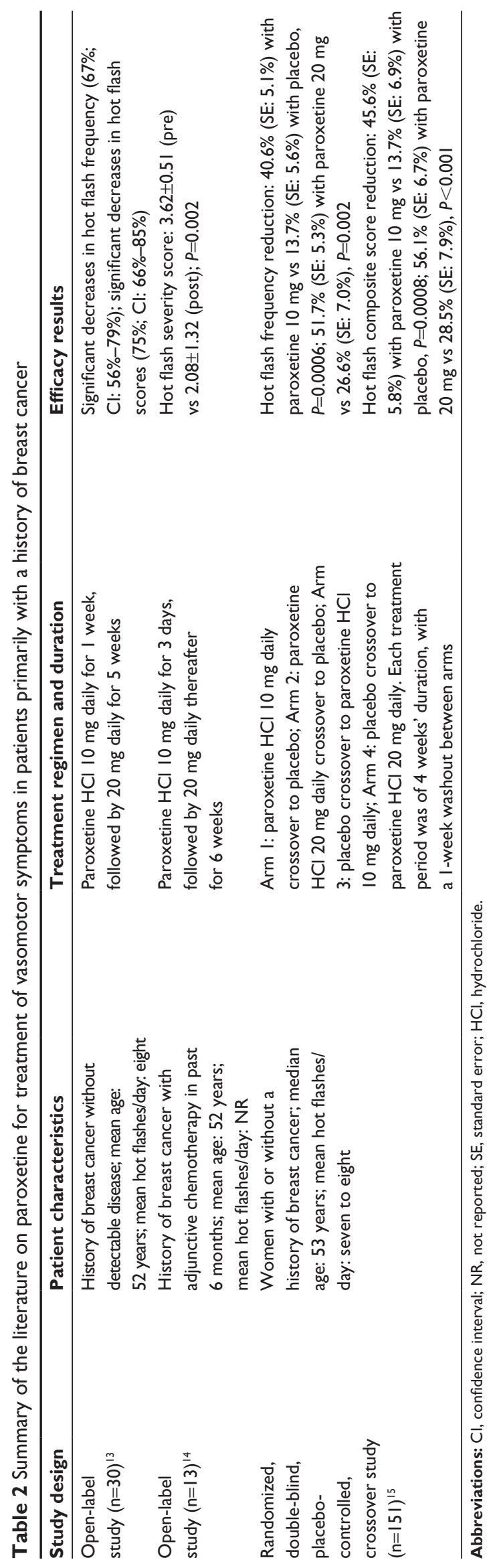


lost to follow-up for incomplete or missing data, and $17(11 \%)$ patients withdrew due to adverse effects. The majority of the withdrawals were in the $20 \mathrm{mg}$ paroxetine $\mathrm{HCl}$ group $(\mathrm{n}=13)$, with fewer in the $10 \mathrm{mg}$ paroxetine $\mathrm{HCl}$ group $(\mathrm{n}=4)$. The most commonly reported adverse effects were drowsiness and nausea. Strengths of this study included the trial design that utilized patients as their own control and the utilization of a hot flash diary to record frequency and severity. Limitations of this study included the small study population, short study duration, lack of a dose titration, only a single-week washout period, significant loss to follow-up, high withdrawal rates, and study population that consisted largely of breast cancer survivors $(81 \%)$, with $64 \%$ of those taking tamoxifen or raloxifene, which are associated with hot flashes.

\section{Summary of paroxetine use in populations primarily with a history of breast cancer}

In the summarized literature, paroxetine $\mathrm{HCl}$ was associated with a $40 \%-67 \%$ reduction in hot flash frequency ${ }^{13,15}$ with 4-6 weeks of treatment compared to $14 \%-27 \%$ reductions with placebo (Table 2). ${ }^{15}$ It was also associated with significant reductions in hot flash severity. ${ }^{15}$ The benefits of paroxetine $\mathrm{HCl}$ on VMS were observed within 1-2 weeks of therapy and were shown to persist throughout a 6-week treatment duration in this patient population. ${ }^{13-15}$ These trials showed both doses of paroxetine $\mathrm{HCl}-10 \mathrm{mg}$ and $20 \mathrm{mg}$ - to be effective for VMS, ${ }^{13-15}$ but the $10 \mathrm{mg}$ dose was better tolerated. ${ }^{15}$

Tamoxifen, a selective estrogen receptor modulator (SERM), is a targeted chemotherapeutic agent that competitively inhibits estrogen. ${ }^{21,22}$ For the $75 \%$ of breast cancers that are estrogen receptor positive, tamoxifen may be considered at any stage but it is frequently used as adjuvant treatment for 2-6 years after primary treatment to prevent recurrence. ${ }^{22-26}$ The medication can be given to both pre- and postmenopausal women. Up to $80 \%$ of patients who take tamoxifen experience hot flashes as an adverse event, necessitating the need to consider treatment for VMS. ${ }^{21}$

There is a significant drug interaction between tamoxifen and paroxetine that clinicians should be aware of in this patient population. Paroxetine inhibits CYP2D6, a cytochrome P450 enzyme that converts the prodrug tamoxifen to active metabolites, and thus may decrease the effectiveness of tamoxifen. ${ }^{7,27}$ An in vivo study of 12 women found that paroxetine decreased the mean serum concentration of the active metabolite endoxifen by $6.9 \mathrm{ng} / \mathrm{mL}$ (CI: $2.7-11.2 \mathrm{ng} / \mathrm{mL}$; $P=0.004) .{ }^{27}$ A study of 80 newly diagnosed breast cancer patients found that women taking potent CYP2D6 inhibitors, including paroxetine, had levels of endoxifen that were $58 \%$ lower (CI: -86.1 to $-19.5 ; P=0.0025){ }^{28}$

Beyond the pharmacokinetic studies, ${ }^{27,28}$ a cohort study of 2,430 women breast cancer survivors who were prescribed an SSRI and tamoxifen were assessed for all-cause mortality and breast cancer mortality. ${ }^{29}$ Women in this cohort who were prescribed and took paroxetine had increased breast cancer mortality. The risk was increased further based on the proportion of time tamoxifen administration overlapped with paroxetine administration (overlap percentage of $25 \%$ for administration time produced $24 \%$ increase, $50 \%$ overlap resulted in a $54 \%$ increase, and $75 \%$ overlap generated $91 \%$ increase; $P<0.05$ for all). On the basis of the results from this study, there would be an additional death from breast cancer for every 19.7 patients who simultaneously received paroxetine and tamoxifen $41 \%$ of the time (median overlap in this study population). The risk with more extensive overlap would be even greater. ${ }^{29}$ This increased risk was not found with the other SSRIs investigated in the study.

As a result of this interaction resulting in decreased efficacy of tamoxifen, both the National Comprehensive Cancer Network (NCCN) and the American Society of Clinical Oncology recommend using caution with concomitant use of paroxetine and tamoxifen., ${ }^{5,30}$ Furthermore, the NCCN and IMS specifically prefer citalopram and venlafaxine over paroxetine and fluoxetine. ${ }^{7,22}$

\section{Study populations primarily without breast cancer}

The safety and efficacy of paroxetine for the treatment of VMS in postmenopausal women primarily without a history of breast cancer have been evaluated in four randomized, double-blind, placebo-controlled trials. ${ }^{10-12}$ The first RCT to evaluate the role of paroxetine for the treatment of VMS in a menopausal population without a history of breast cancer was conducted in 165 women with at least two to three hot flashes per day or 14 hot flashes per week. ${ }^{11}$ Patients were randomized to receive paroxetine $\mathrm{HCl}$ controlled release (CR) (12.5 mg or $25 \mathrm{mg}$ ) or placebo daily for 6 weeks after a 1-week run-in phase. The primary objective evaluated was hot flash composite score (Table 1). Patients had a mean of 6.7 hot flashes per day, and only $7.3 \%$ had a history of breast cancer. When compared to placebo, both the $12.5 \mathrm{mg}(62.2 \%$ vs $37.8 \% ; P=0.007)$ and $25 \mathrm{mg}(64.6 \%$ vs $37.8 \% ; P=0.03$ ) paroxetine $\mathrm{HCl} \mathrm{CR}$ groups demonstrated a significant reduction in mean hot flashes composite scores at 6 weeks. The majority of adverse events reported (58.3\% in paroxetine vs $53.6 \%$ in placebo) were of mild-to-moderate 
severity and consistent with the established adverse effects of paroxetine. The most common adverse events associated with paroxetine $\mathrm{HCl} \mathrm{CR}$ therapy were headache, dizziness, nausea, and insomnia, with lower frequencies in the $12.5 \mathrm{mg}$ group than the $25 \mathrm{mg}$ group. Strengths of this trial include a population of subjects who were not primarily breast cancer survivors, a low percentage (7.3\%) of patients taking SERM therapy, the evaluation of paroxetine $12.5 \mathrm{mg}$ and $25 \mathrm{mg}$ doses, and the utilization of a CR formulation, which is better tolerated. Limitations include a small sample size studied over a short duration, lack of dose titration, and a limited racial group representation ( $87 \%$ white).

The second RCT trial was conducted in 56 perimenopausal and postmenopausal patients who reported VMS after discontinuation of HT. ${ }^{12}$ Patients with at least 14 hot flashes per week of moderate-to-severe severity (GCS vasomotor subscore $>3$, Table 1) were randomized to paroxetine $\mathrm{HCl}$ CR $12.5 \mathrm{mg}$ or placebo daily after a 1-week lead-in phase, with the option to titrate to $25 \mathrm{mg}$ daily at Week 2 based on treatment response and tolerability. The primary outcome was change in VMS from baseline to Week 6. Patients in the paroxetine $\mathrm{HCl} \mathrm{CR}$ group reported significant median reduction in weekly VMS when compared to placebo (6.1 [interquartile range $\{\mathrm{IQR}\}=2.7-6.8$ ] vs 2.8 [IQR $=0.1-4.5]$, respectively; $P=0.03$ ), with $63 \%$ of subjects in the paroxetine $\mathrm{HCl} \mathrm{CR}$ group titrated to $25 \mathrm{mg}$ daily at Week 2 . Changes in the GCS subscore for the reduction in VMS were also noted to be superior for paroxetine $(P=0.04)$, although the authors did not report results. There were no significant differences reported in terms of adverse effects. Similarly to the previous study, strengths include a more general population without a history of breast cancer and use of the CR formulation. Dose titration based on response and tolerability is an additional strength. Important limitations to note include a small sample size, short study duration, variable timelines of previous HT, and a predominantly white population (86\%).

More recently, Simon et a ${ }^{10}$ conducted two similarly designed larger Phase III pivotal clinical trials (614 and 570 patients, respectively) to evaluate the safety and efficacy of low-dose paroxetine mesylate (LDPM) in postmenopausal women with moderate-to-severe VMS. Participants had to have at least seven to eight hot flashes per day or 50-60 hot flashes per week, a higher frequency than in previously described populations. Patients were randomly assigned to receive paroxetine mesylate $7.5 \mathrm{mg}$ at bedtime or placebo for 12 weeks and 24 weeks, the longest of trial durations to date. The two primary outcomes measured were the changes in mean hot flash frequency and severity (Table 1). Patients had an average of 11.3 hot flashes per day. In both studies, patients in the paroxetine mesylate group had significantly greater reductions in mean weekly VMS frequency at both 4-week (12-week study: -33.0 and -23.5 , respectively, $P<0.0001$; 24-week study: -28.9 and -19.0 , respectively, $P<0.0001)$ and 12 -week assessments (12-week study: -43.5 and -37.3 , respectively, $P=0.0090 ; 24$-week study: -37.2 and -27.6 , respectively, $P=0.0001$ ). The paroxetine mesylate group also had significantly greater reductions in mean weekly VMS severity at Week $4(P=0.0048)$ but not at Week $12(P=0.2893)$ in the 12 -week study, while significant reductions were observed at both Week 4 and Week 12 in the 24-week study ( $P=0.0452$ and $P=0.0114$, respectively).

To assess the clinical meaningfulness of the reduction in VMS frequency, the PGI-I questionnaire was administered to evaluate the patients' perception of improvement (Table 1). At Week 4, there were significantly more responders in the paroxetine group than in the placebo group (58.5\% vs $47.2 \%$, respectively, $P<0.0058)$, but not at Week 12 (47.8\% vs $41.6 \%$, respectively, $P<0.1332) .{ }^{10}$ An additional outcome in the 24-week study evaluated the persistence of treatment benefit (defined as patients who achieved at least a 50\% reduction in moderate-to-severe hot flash frequency from baseline to Week 24). The benefit of treatment extended through 24 weeks in $47.5 \%$ of those in the paroxetine group and $36.3 \%$ of women in the placebo group $(P=0.0066)$. Treatment-emergent adverse events were generally similar between paroxetine and placebo groups, with at least a twofold higher frequency of nausea, fatigue, and dizziness reported in the paroxetine group, although all incidences reported were $<4 \%$. Additionally, the authors stated that the Discontinuation-Emergent Signs and Symptoms (DESS) scale results did not reveal any meaningful differences between the paroxetine mesylate and placebo group after discontinuation without tapering, although the DESS scale results were not presented.

A major strength of these two trials is the generalizability of results to a relatively healthy population without a history of breast cancer and a majority of participants with naturally occurring menopause. However, the results may be limited for patients with surgically induced menopause. Further strengths include extended study durations, evaluation of a lower dose $(7.5 \mathrm{mg})$ to minimize adverse effects and withdrawal symptoms, a validated real-time electronic hot flash diary, and the exclusion of SERM therapy to limit drug interactions. Two limitations involve the lack of an active comparator arm such as HT and that the study population was predominantly white $(70 \%)$.

Supplementary publications from this study population presented results on sleep disturbances and evaluated the 
effect of treatment on weight and sexual dysfunction in a pooled analysis. ${ }^{31,32}$ Patients reported a baseline mean of 3.6 awakenings per night due to VMS. They found a significant reduction in nighttime awakening due to VMS at 4 weeks (39\% reduction for paroxetine vs $28 \%$ placebo; $P=0.0049$ ), and these results were sustained through the 24 -week treatment period ( $62 \%$ reduction for paroxetine vs $43 \%$ placebo; $P<0.0001)$. The paroxetine mesylate group also had significantly increased nighttime sleep duration at all assessments, but no differences were found in sleep-onset latency or sleep-related adverse events such as sedation. ${ }^{27}$ In the pooled analysis evaluation of the treatment's effect on weight and sexual dysfunction, there were no statistically significant changes observed from baseline in terms of weight or sexual function in the paroxetine mesylate $7.5 \mathrm{mg}$ group. ${ }^{32}$

\section{Summary of paroxetine use in populations primarily without breast cancer}

In the summarized literature, paroxetine $(\mathrm{HCl}$ and mesylate salts) was associated with a $33 \%-65 \%$ reduction in hot flash frequency with 6-12 weeks of treatment compared to $17 \%-38 \%$ reductions with placebo (Table 3 ). ${ }^{10-12}$ Paroxetine was also associated with significant reductions in hot flash severity ${ }^{10-12}$ and patient-perceived improvement at 4 weeks, although patient-perceived improvement did not remain significant at 12 weeks. ${ }^{10}$ A reduction in hot flash frequency was observed within 2 weeks of therapy ${ }^{10-12}$ and persisted throughout a 24-week treatment duration. ${ }^{10}$ Although most literature supporting use of paroxetine consists of doses between $10 \mathrm{mg}$ and $25 \mathrm{mg}$, significant reductions in VMS were observed with the LDPM $(7.5 \mathrm{mg} /$ day $)$, with a tolerable adverse effect profile and no significant withdrawal symptoms at discontinuation without tapering. ${ }^{11}$

\section{Discussion}

HT is considered to be the most effective treatment for VMS. In women with a history of breast cancer, HT is contraindicated, and alternative therapies, such as SSRIs, are needed to manage VMS. It is important to remember that sometimes the severity of VMS in this patient population can be severe secondary to earlier age of onset, abruptness of onset (chemotherapy induced or surgically induced), and/or use of antiestrogen medications as adjunctive therapy to treat the patient's breast cancer. Additionally, HT may not be appropriate for patients with contraindications or precautions other than a history of breast cancer, such as those with significant cardiovascular disease, a history of thromboembolism, or conditions exacerbated by HT. ${ }^{2}$ Patients may also be unwilling to take HT because of associated risks or lack of tolerability. Due to the limitations of HT, safe and effective alternative therapies are needed.

SSRIs have been utilized and acknowledged by several guideline publications as alternative therapy to HT for the treatment of VMS. ${ }^{2,3}$ Although existing data appear to indicate that HT is more efficacious than SSRIs, the lack of direct comparisons limits this conclusion. ${ }^{2}$ RCTs with active comparators are necessary to determine the most effective therapy for VMS. While several SSRIs have been used offlabel for alternative therapy, paroxetine mesylate $7.5 \mathrm{mg}$ (Brisdelle $^{\circledR}$; Noven Therapeutics, LLC) received attention when it was approved for the treatment of moderate-to-severe VMS in the USA. ${ }^{2}$ It is important to note the modest treatment benefit when compared to placebo observed in the two RCTs supporting its approval. ${ }^{10}$ A majority of the US FDA Advisory Committee for Reproductive Health Drugs panel did not support the approval of paroxetine mesylate for VMS treatment based on its overall risk-benefit profile and modest efficacy. Although the advisory panel's concerns were taken into consideration, FDA approval was granted due to patients' perception of benefit, the persistence of treatment effect at 24 weeks, the large avoidance of safety concerns with appropriate patient selection, and the unmet need for nonhormonal therapy options for VMS management. ${ }^{33}$

Paroxetine mesylate offers the lowest available dose of $7.5 \mathrm{mg}$ but is only available in the USA under the brand name Brisdelle $^{\circledR}$ (Noven Therapeutics, LLC). Consequently, this particular formulation is more expensive than other generic paroxetine $\mathrm{HCl}$ formulations (Table 4). ${ }^{34}$ Although there are minor pharmacokinetic differences between the $\mathrm{HCl}$ and mesylate salts, there is no evidence that they have any clinical meaningfulness. The $\mathrm{HCl}$ and mesylate salts are both inactive and disassociate from active paroxetine in the gastrointestinal tract. ${ }^{17}$ Because both salts have demonstrated efficacy in clinical trials, initiating therapy with paroxetine $\mathrm{HCl} 10 \mathrm{mg}$ or $12.5 \mathrm{mg}$ CR may be an option when availability or cost is an issue. Paroxetine ( $\mathrm{HCl}$ and mesylate) exhibits nonlinear pharmacokinetics due to saturable CYP2D6 metabolism, and therefore dose adjustments can lead to disproportional changes in plasma drug levels. ${ }^{17,35}$ Consequently, increases in concentration-dependent adverse effects may be observed with dose increases. Although there are no direct comparisons among the $7.5 \mathrm{mg}, 10 \mathrm{mg}$, and $12.5 \mathrm{mg}$ doses, tolerability is comparable based on adverse event rates in similar patient populations. ${ }^{10-12}$ Moreover, there is currently no head-tohead evidence that doses of 20-25 mg provide significantly greater relief than doses $\leq 12.5 \mathrm{mg}$, and the $25 \mathrm{mg}$ dose was associated with increased frequencies of adverse effects. ${ }^{12}$ 


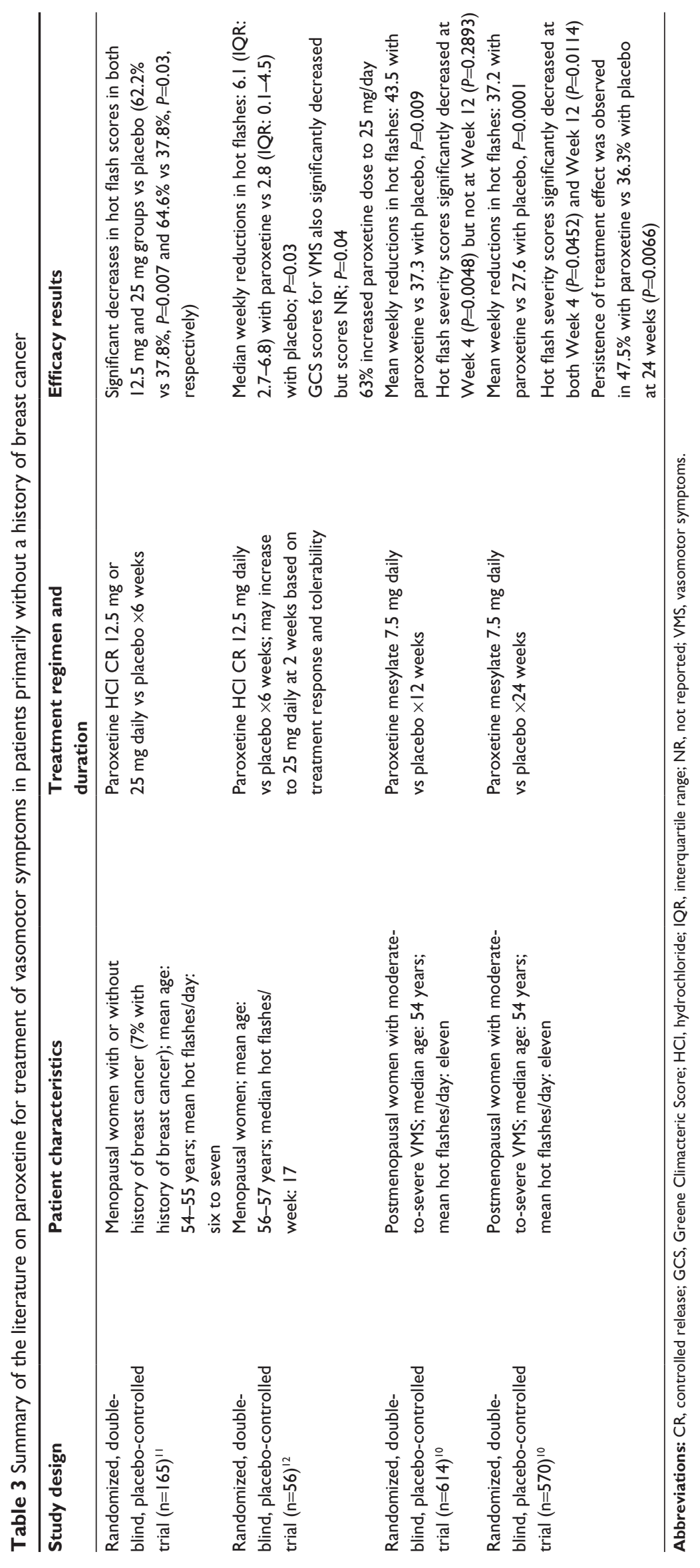


Table 4 Available paroxetine formulations in the USA and associated cost

\begin{tabular}{lll}
\hline Drug & Available formulations & AWP cost (30-day supply) \\
\hline Paroxetine HCl & Generic I0 mg, $20 \mathrm{mg}, 30 \mathrm{mg}, 40 \mathrm{mg}$ tablets & $\$ 78.56$ (10 mg) \\
& Generic CR I2.5 mg, $25 \mathrm{mg}, 37.5 \mathrm{mg}$ tablets & $\$ 108.63(12.5 \mathrm{mg})$ \\
& aPaxil I0 mg, $20 \mathrm{mg}, 30 \mathrm{mg}, 40 \mathrm{mg}$ tablets & $\$ 163.85(10 \mathrm{mg})$ \\
& aPaxil CR I2.5 mg, $25 \mathrm{mg}, 37.5 \mathrm{mg}$ tablets & $\$ 168.76(12.5 \mathrm{mg})$ \\
Paroxetine mesylate & aPaxil I0 mg/5 mL suspension & $\$ 284.45(250 \mathrm{~mL})$ \\
& 'Brisdelle $7.5 \mathrm{mg}$ capsules & $\$ 161.64$ \\
\hline
\end{tabular}

Notes: a $G$ laxoSmithKline LLC, Research Triangle Park, NC, USA; 'Doven Therapeutics, LLC, Miami, FL, USA. Adapted with permission from Paroxetine. In: RED BOOK [AUHSOP intranet database]. Greenwood Village, CO: Truven Health Analytics [updated daily]. Available from: http://www.micromedexsolutions.com/micromedex2/ librarian/ND_T/evidencexpert/ND_PR/evidencexpert/CS/9F9DDB/ND_AppProduct/evidencexpert/DUPLICATIONSHIELDSYNC/49D885/ND_PG/evidencexpert/ND_B/ evidencexpert/ND_P/evidencexpert/PFActionld/redbook.FindRedBook?navitem=topRedBook. Accessed December 14, $2014 .^{34}$

Abbreviations: AWP, average wholesale price; $\mathrm{CR}$, controlled release; $\mathrm{HCl}$, hydrochloride.

Therefore, it is prudent to initiate therapy at the lowest available dose and only consider a dose titration in patients with an insufficient response after an adequate trial (ie, 2 weeks) because some patients may benefit from dose increases. ${ }^{12}$

The most common adverse effects reported in the studies $^{10-15}$ include somnolence, fatigue, headache, gastrointestinal effects (which include nausea, increased appetite, and constipation), dry mouth, insomnia, weight gain, and weakness. These are similar to adverse effects commonly reported with paroxetine use in other patient populations. The serotonin-mediated adverse effects are considered to be dose dependent. ${ }^{35}$ If the patient experiences fatigue or somnolence, the medication should be administered at bedtime. For patients receiving doses $>7.5 \mathrm{mg}$ for at least 1 week, it is recommended to taper therapy at discontinuation to limit common withdrawal symptoms such as headache, agitation, and sleep disturbances. ${ }^{35}$ Patients should be monitored for common adverse effects during treatment as well as for discontinuation-emergent symptoms. Other important precautions associated with paroxetine therapy include CYP2D6 drug interactions, increased fracture risk, and possible serotonin syndrome due to pharmacodynamic interactions with other agents that affect serotonin levels..$^{35}$

\section{Future directions}

Further trials are needed to fully determine the role of paroxetine for relief of menopausal hot flashes. Trials should include a larger number of participants in more diverse demographic populations for longer trial durations ( $>24$ weeks). Extended treatment durations are needed to differentiate whether the results can be sustained or if the patient is experiencing a natural decrease in menopausal symptoms. In addition, extended study treatments would allow researchers to discriminate whether the effect achieved was legitimate or simply a placebo effect. The results should also be reported as impact on both natural and surgical menopause, separately.
Finally, RCTs with active comparators are still needed to determine efficacy relative to HT.

\section{Conclusion}

The current evidence indicates that paroxetine $(\mathrm{HCl}$ and mesylate) is a safe and effective therapy for the treatment of VMS that may accompany menopause regardless of a history of breast cancer. Paroxetine $\mathrm{HCl}$ or mesylate $(7.5-12.5 \mathrm{mg} /$ day) should be considered a first-line therapy option for VMS in patients for whom HT is either inappropriate or intolerable. RCTs with active comparators are still needed to determine the most effective treatment for VMS. It is recommended to use the lowest available dose to minimize adverse effects and discontinuation-emergent symptoms. Patient-specific characteristics and treatment needs should be considered to individualize treatment and monitor for adverse effects.

\section{Disclosure}

The authors report no conflicts of interest in this work.

\section{References}

1. Gold EB. The timing of the age at which natural menopause occurs. Obstet Gynecol Clin North Am. 2011;38(3):425-440.

2. American College of Obstetricians and Gynecologists. Practice Bulletin No 141: management of menopausal symptoms. Obstet Gynecol. 2014;123:202-216.

3. Goodman NF, Cobin RH, Ginzburg SB, Katz IA, Woode DE. American Association of Clinical Endocrinologists medical guidelines for clinical practice for the diagnosis and treatment of menopause. Endocr Pract. 2011;17(suppl 6):1-25.

4. Archer DF, Sturdee DW, Baber R, et al. Menopausal hot flushes and night sweats: where are we now. Climacteric. 2011;14(5):515-528.

5. North American Menopause Society. The 2012 hormone therapy position statement of The North American Menopause Society. Menopause. 2012;19(3):257-271.

6. de Villiers TJ, Gass ML, Haines CJ, et al. Global consensus statement on menopausal hormone therapy. Maturitas. 2013;74(4):391-392.

7. de Villiers TJ, Pines A, Panay N, et al. Updated 2013 International Menopause Society recommendations on menopausal hormone therapy and preventive strategies for midlife health. Climacteric. 2013;16(3): 316-337. 
8. Maclennan AH, Broadbent JL, Lester S, Moore V. Oral oestrogen and combined oestrogen/progestogen therapy versus placebo for hot flushes. Cochrane Database Syst Rev. 2004;(4):CD002978.

9. Modena MG, Sismondi P, Mueck AO, et al. Risks and benefits of estrogen plus progestin in healthy menopausal women: principle results from the Women's Health Initiative randomized controlled trial. JAMA. 2002;288:321-333.

10. Simon JA, Portman DJ, Kaunitz AM, et al. Low-dose paroxetine $7.5 \mathrm{mg}$ for menopausal vasomotor symptoms: two randomized controlled trials. Menopause. 2013;20(10):1027-1035.

11. Stearns V, Beebee KL, Iyengar M, Dube E. Paroxetine controlled release in the treatment of menopausal hot flashes: a randomized controlled trial. JAMA. 2003;289:2827-2834.

12. Soares CN, Joffe H, Viguera AC, et al. Paroxetine versus placebo for women in midlife after hormone discontinuation. Am J Med. 2008; 121:159-162.

13. Stearns $V$, Isaacs $C$, Rowland J, et al. A pilot trial assessing the efficacy of paroxetine hydrocholoride (Paxil) in controlling hot flashes in breast cancer survivors. Ann Oncol. 2000;11:17-22.

14. Weitzner MA, Moncello J, Jacobsen PB, Minton S. A pilot trial of paroxetine for the treatment of the hot flashes and associated symptoms in women with breast cancer. J Pain Symptom Manage. 2002;23(4):337-345.

15. Stearns V, Slack R, Greep N, et al. Paroxetine is an effective treatment for hot flashes: results from a prospective randomized clinical trial. J Clin Oncol. 2005;23(28):6919-6930.

16. U.S. Department of Health and Human Services, Food and Drug Administration, Advisory Committee for Reproductive Health Drugs. Paroxetine Mesylate for Treatment of Moderate to Severe Vasomotor Symptoms Associated with Menopause [updated March 4, 2013]. Available from: http://www.fda.gov/downloads/AdvisoryCommittees/ CommitteesMeetingMaterials/Drugs/ReproductiveHealthDrugsAdvisoryCommittee/UCM343175.pdf. Accessed October 24, 2014.

17. Catelli M, Bhaskar S, Lippman J. Pharmacokinetic properties of once-daily oral low-dose mesylate salt of paroxetine (LDMP $7.5 \mathrm{mg}$ ) following single and multiple doses in healthy postmenopausal women. Clin Ther. 2013;35(6):862-869.

18. Cubeddu A, Giannini A, Bucci F, et al. Paroxetine increased brain derived neurotrophic factor in menopausal women. Menopause. 2010; 17(2):338-343.

19. Yasui T, Yamada M, Uemura H, et al. Changes in circulating cytokine levels in midlife women with psychological symptoms with selective serotonin reuptake inhibitor and Japanese traditional medicine. Maturitas. 2009;62(2):146-152.

20. Ushiroyama T, Ikeda A, Ueki M. Evaluation of double-blind comparison of fluvoxamine and paroxetine in the treatment of depressed outpatients in menopause transition. $J$ Med. 2004;35(1-6):151-162.

21. Nolvadex (tamoxifen citrate) [package insert]. Wilmington, Delaware: AstraZeneca Pharmaceuticals LP [updated August, 2004]. Available from: http://www.accessdata.fda.gov/drugsatfda_docs/ label/2005/17970s053lbl.pdf. Accessed February 6, 2015.

22. National Comprehensive Cancer Network. Breast cancer (Version 3. 2014) [updated 2014]. Available from: http://www.nccn.org/professionals/ physician_gls/pdf/breast.pdf. Accessed October 29, 2014.

23. Burstein HJ, Temin S, Anderson H, et al. Adjuvant endocrine therapy for women with hormone receptor-positive breast cancer: American Society of Clinical Oncology clinical practice guideline focused update. J Clin Oncol. 2014;32(21):2255-2269.
24. Visvanathan K, Hurley P, Bantug E. Use of pharmacologic interventions for breast cancer risk reduction: American Society of Clinical Oncology clinical practice guideline. J Clin Oncol. 2013;31(23): 2942-2962.

25. National Institute for Health and Care Excellence. Advanced breast cancer, diagnosis and treatment [updated 2014]. Available from: http:// www.nice.org.uk/guidance/cg81/resources/guidance-advanced-breastcancer-update-pdf. Accessed December 29, 2014.

26. National Institute for Health and Care Excellence. Early and locally advanced breast cancer, diagnosis and treatment [updated 2014]. Available from: http://www.nice.org.uk/guidance/cg80/resources/ guidance-early-and-locally-advanced-breast-cancer-pdf. Accessed December 29, 2014

27. Stearns V, Johnson MD, Rae JM, et al. Active tamoxifen metabolite plasma concentrations after coadministration of tamoxifen and the selective serotonin reuptake inhibitor paroxetine. J Natl Cancer Inst. 2003;95(23):1758-1764.

28. Jin Y, Desta Z, Stearns V, et al. CYP2D6 genotype, antidepressant use, and tamoxifen metabolism during adjuvant breast cancer treatment. J Natl Cancer Inst. 2005;97(1):30-39.

29. Kelly CM, Juurlink DN, Gomes T, et al. Selective serotonin reuptake inhibitors and breast cancer mortality in women receiving tamoxifen: a population based cohort study. BMJ. 2010;340:c693.

30. American Society of Clinical Oncology. Adjuvant endocrine therapy for women with hormone receptor-positive breast cancer: American Society of Clinical Oncology clinical practice guideline focused update. Data supplement [updated 2014]. Available from: http://www. instituteforquality.org/sites/instituteforquality.org/files/adju_endo_ upd_data_supplement_2014_0.pdf. Accessed December 29, 2014.

31. Pinkerton JV, Joffe H, Kazenpour K, Mekonnen H, Bhaskar S, Lippman J. Low-dose paroxetine (7.5 $\mathrm{mg}$ ) improves sleep in women with vasomotor symptoms associated with menopause. Menopause. 2015;22(1):50-58.

32. Portman DJ, Kaunitz AM, Kazempour K, Mekonnen H, Bhaskar S, Lippman J. Effects of low-dose paroxetine $7.5 \mathrm{mg}$ on weight and sexual function during treatment of vasomotor symptoms associated with menopause. Menopause. 2014;21(10):1082-1090.

33. Joffe HV. Division Director's Summary Review for Approval of Brisdelle (paroxetine mesylate) [updated June 28, 2013]. Available from: http://www. accessdata.fda.gov/drugsatfda_docs/nda/2013/204516Orig1s000SumR. pdf. Accessed March 19, 2015.

34. Paroxetine. In: RED BOOK [AUHSOP intranet database]. Greenwood Village, CO: Truven Health Analytics [updated daily]. Available from: http://www.micromedexsolutions.com/micromedex2/librarian/ ND_T/evidencexpert/ND_PR/evidencexpert/CS/9F9DDB/ND_AppProduct/evidencexpert/DUPLICATIONSHIELDSYNC/49D885/ ND_PG/evidencexpert/ND_B/evidencexpert/ND_P/evidencexpert/ PFActionId/redbook.FindRedBook?navitem=topRedBook. Accessed December 14, 2014.

35. Paxil CR. (paroxetine hydrochloride) controlled release tablets [package insert]. Mississauga, ON: GlaxoSmithKline Inc [updated March, 2014]. Available from: http://www.gsk.ca/english/docs-pdf/productmonographs/Paxil-CR.pdf. Accessed October 24, 2014.

\section{Dovepress}

\section{Publish your work in this journal}

The International Journal of Women's Health is an international, peerreviewed open-access journal publishing original research, reports, editorials, reviews and commentaries on all aspects of women's healthcare including gynecology, obstetrics, and breast cancer. The manuscript management system is completely online and includes

a very quick and fair peer-review system, which is all easy to use. Visit http://www.dovepress.com/testimonials.php to read real quotes from published authors. 